\title{
Electron transfer from bacteria to minerals: mechanisms and mediation for environmental application
}

\author{
FANGBAI Li*, LIPING FANG, TONGXU LIU
}

Guangdong Institute of Eco-Environ Sci \& Technol, Guangzhou 510650, China (cefbli@soil.gd.cn).

The widespread persistent organic compounds and heavy metals pollution in surface soils and waters is a global challenge, which can be hardly resolved with traditional approaches. In view of the occurrence of the transformation of these pollutants in biogeochemical processes, in-depth insight into their driving forces and the underlying mechanisms may shed new light on regulating pollutants in nature. Herein, this work focuses on the key processes and mechanisms of extracellualar electron transfer (EET) from bacteria to minerals and the key merits of this work are illustrated in scheme 1.

Scheme 1. The mechanisms of EET from bacteria to minerals and

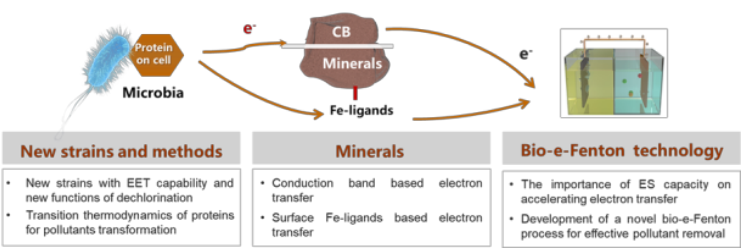

the environmental application

For the first time, nine bacterial species from soils (e.g. Klebsiella pneumoniae L17) with new functions like dechlorination have been identified and hereby, a novel spectroelectrochemical method was developed enabling the determination of the transition kinetic rate of cytochrome $\mathrm{c}$ on the bacterial surface; our study further shows that highly active Fe(III) and $\mathrm{Fe}(\mathrm{II})$-ligand species on the surface of minerals can determine the rate of EET by minerals, and the coupling of cytochrome $\mathrm{c}$ to $\mathrm{Fe}$ minerals (e.g. $\alpha-\mathrm{Fe}_{2} \mathrm{O}_{3}$ ) can shift the conduction band (CB) favoring the electron transport in the bulk phase of the minerals. The above evidence demonstrates the importance of the surface Fe-ligands and $\mathrm{CB}$ in determining the EET efficiency of minerals; accordingly, a series of new porous materials (e.g. PPy/AQDS) have been developed and incorporated into a novel bio-e-Fenton reaction system, which advances the electron efficiency up to $89 \%$, and enhances the removal rate of arsenic by 2.3 times than the traditional Fenton-like reaction. In conclusion, our research consolidates the understanding of EET between bacteria and minerals and offers new perspectives for regulating pollutants in surface soils and waters. 